\title{
Faulty Crowns Corrected by all Ceramic Crowns - A Case Report
}

\author{
Authors \\ Jacob J Hendrick ${ }^{1^{*}}$, Kottor $\mathrm{K}^{2}$ \\ ${ }^{1}$ *Assistant Professor, Department of Prosthodontics, KMCT Dental College (India) \\ ${ }^{2}$ PostgraduateStudent, Department of Prosthodontics, KMCT Dental College, (India) \\ *Corresponding Author \\ Jacob J Hendrick
}

\section{Abstract}

All ceramic restorative materials used as single crown restorations for endodontically treated teeth have gained popularity due to its high esthetic effect. However, proper contours of such crowns are important, otherwise its impact on the periodontium renders it unaesthetic. A female patient aged 26 years reported to the department of prosthodontics with chief complaint of poor aesthetics in relation to her two single crowns on maxillary central incisors. Clinical examination revealed gingival recession with an exposure of cervical margins, thus rendering the crowns as highly unaesthetic. Faulty crowns were removed and tooth preparation was modified following which two new all ceramic crowns were cemented. The patient's esthetic appearance improved which directly affected her self confidence in displaying the teeth during a smile.

Keywords:metal-ceramic, zirconia, alumina, resin cement, tooth preparation.

\section{Introduction}

Patient demand for aesthetics in universal and across all ages. Even elderly patients who are completely edentulous reject their complete denture prosthesis if esthetics are not satisfactory. ${ }^{1}$ For young patients, especially the female gender, esthetics is the primary reason they seek dental treatment. Anterior aesthetic fixed partial denture rehabilitation has traditionally been done with metal, ceramic restorations for a long time since $1970 .^{2}$ For a long period, the metal backing for ceramic dominated crown and bridge restorations, till the advent of zirconia reinforced ceramics took over. ${ }^{3}$ Zirconia systems have undergone modifications over the years to overcome the problems like brittleness and strength. Although metal-ceramic systems have a long survival rate, the advantages of all ceramic systems in terms of translucency and vitality without the grayish effect of metal has seen all ceramic restorations a common replacement for metal ceramic crowns.

All ceramic zirconia systems are similar in fabrication like metal-ceramic in that a coping is to be fabricated first, followed by fusing of the porcelain over the zirconia coping. The clinician should have a thorough understanding of the dimensions of the final crown that will be fabricated by the laboratory. Inadequate tooth preparation for the final crown leads to an over contoured crown which has a direct bearing on the periodontium. The following case report is an example of one such iatrogenic error in crown fabrication.

\section{Case Report}

A young female patient aged 23 years reported to the department of prosthodontics with a chief complaint of poor aesthetics of two maxillary front crowns fabricated 3years back by a local dentist. 


\section{JMSCR Vol||07||Issue||11||Page 773-776||November}

Patients medical history was noncontributory and non significant to her current condition while dental history revealed orthodontic treatment done four years back by a local dental practitioner. The patient was educated about oral hygiene maintenance as she had undergone dental treatment a number of times in the past. Other dental treatment included endodontic treatment of maxillary central incisors and crown fabrication in relation to the same teeth. Extra oral examination revealed a slightly prognathic mandible while patients lymph node and mandibular movements were within the normal limits. Intra oral examination revealed an edge to edge anterior occlusion in centric occlusion with a cross bite on the left posterior side. The molar and canine relation were anterior to the ideal key of occlusion. Maxillary central incisors were both endodontically treated and had an all ceramic conjoined crown over them (Fig 1). The cervical margins of the crowns were exposed and plaque collection over the exposed tooth surface gave it a brownish appearance thus making the restoration striking when patient smiled. When viewed incisally, both crowns had over contoured middle one third. No other significant abnormality of hard and soft tissue was found. A radiographic investigation was done following which diagnostic impressions were made with irreversible hydrocolloid.

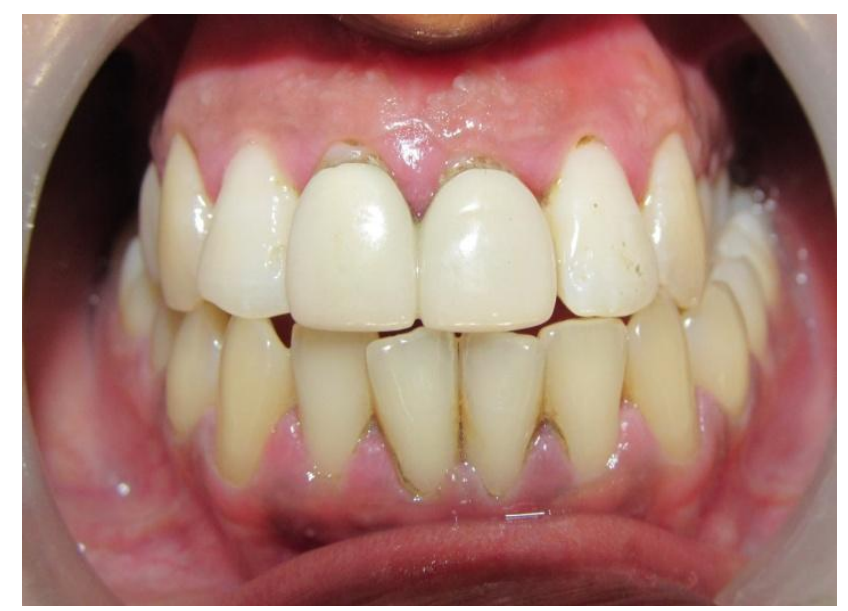

Figure 1: Maxillary central incisors with joined crowns and cervically exposed root surfaces

Diagnostic casts were analyzed for occlusion and a treatment plan was presented to the patient that included removal of the two faulty crowns followed by modification of tooth preparation and definitive restoration in the form of all ceramic crowns. The patient consented to the treatment option while rejecting alternative metal ceramic crowns.

The clinical procedures for fabrication of a single crown were routine. After removal of faulty crowns, the tooth preparation was modified with extension of margins just below the free marginal gingiva. A temporary restoration was fabricated from self cure tooth colored resin (Unifast) and cemented with a temporary cement (Fig 2). Final impressions were made using a dual mix technique on a custom tray. After a coping trial and shade selection, the definitive crowns were cemented with a resin cement (Fig 3). The patient was instructed regarding oral hygiene maintainence of the single crowns. The patient was highly satisfied with the esthetic outcome of the two cemented crowns (Fig 3).

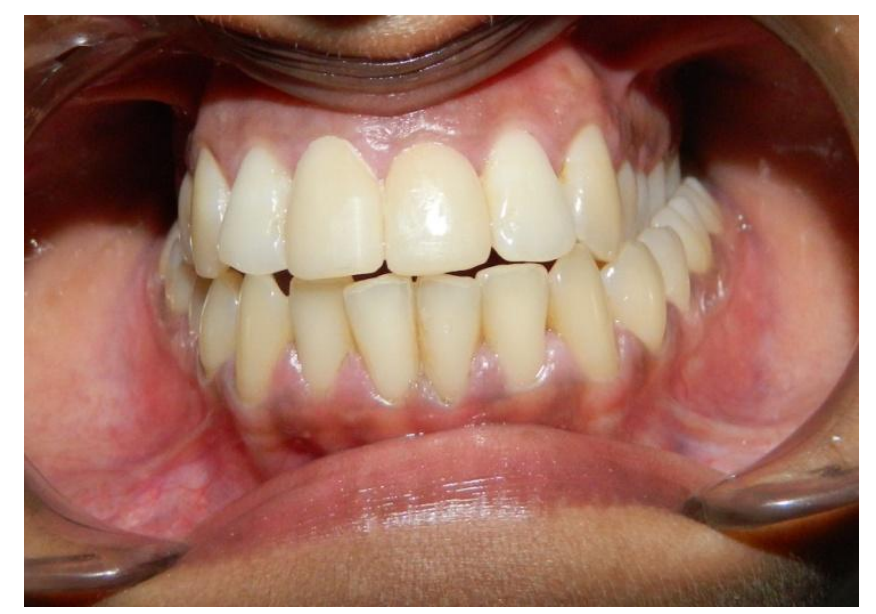

Figure 2: Modified tooth preparation cemented with temporary crowns

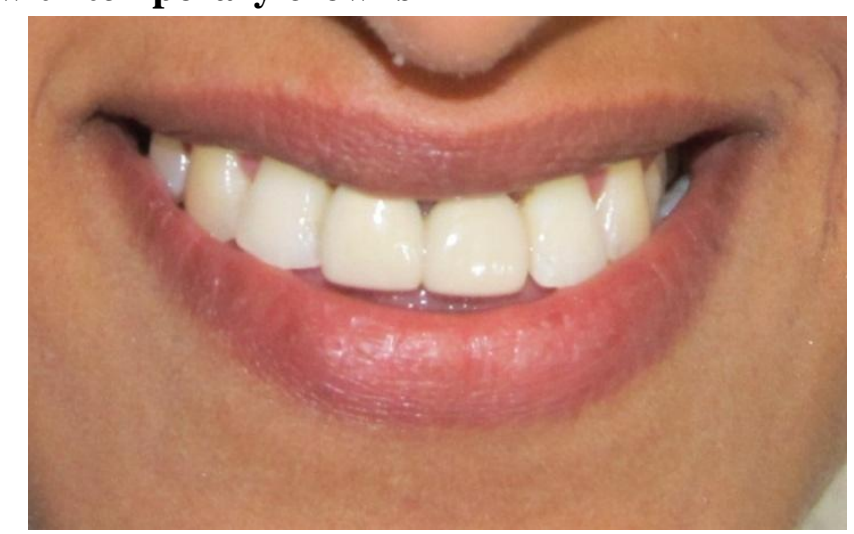

Figure 3: Definitive all ceramic crowns cemented in place. 


\section{Discussion}

Facial aesthetics has many dimensions and as pointed out by Kumar et al, the three dimensions (biological, bio-mechanical and psychological0 should be kept in mind by the dentist and considered for every patient. ${ }^{4}$ the patient in this case report is an example of such phenomenon since patient had become conscious of her crown margin exposure during smiling, she claimed to have restricted her smile in front of her friends. Proper contouring of the crowns is essential for long term periodontal health of the abutment. ${ }^{5}$ In this case the labial over contouring in an already protruded maxilla created an environment for the underlying periodontium where the natural food flow pattern was altered and the periodontium was devoid of natural stimulation from the food. The patient also presented with a gummy smile (Fig 3) which was probably not considered by the previous dentist. While restoring anterior teeth with a crown, the dentist should consider the low lip and the high lip line since the choice between the supra and subgingival finish line depends largely on the high lip line. ${ }^{6,7}$

The transition from metal-ceramic to all ceramic restorarative materials has seen a continuous improvement in zirconia based all ceramic restorations. Since its identification by the german chemist Klaproth, ${ }^{8}$ zirconia based all ceramic restorations have found place in both single crowns and short span anterior fixed partial dentures. ${ }^{9}$ with a flexural strength approximating 900 to $1100 \mathrm{Mpa}$, ${ }^{10}$ the zirconia based fixed partial dentures can be given in dentition where abnormal occlusal forces are minimal. One of such condition where occlusal forces become abnormal is in dentitions with occlusal plane problems. ${ }^{11}$ the present case, despite having gone orthodontic correction of occlusion, yet occlusion was highly unsatisfactory since one side, cross bite did exist and anterior guidance was far from satisfactory. However the final restorations were fabricated in such a way, that little or no occlusal forces would fall on the incisal edge of the single crown restorations and both crowns were designed to be individual for the same reason.
Zirconia coping was fabricated using a CAD/ CAM, while laser scanner (Cynoprod/Canada) scanned the preparation. Besides esthetics in terms of translucency and vitality, the all ceramic crown material has excellent strength, corrosion resistance and biocompatibility. ${ }^{5,12}$

\section{Conclusion}

While designing any type of fixed partial denture the dentist must keep in mind the importance of proper contours on the labial and lingual side to minimize ill effects on the periodontium. Over contoured restorations result in stripping of gingiva with an exposure of root, thus even a good restoration may have impaired esthetics over a period of time

\section{Acknowledgements}

The authors would like to acknowledge the staff of the orthodontic, oral medicine and diagnosis departments and the technicians of the dental laboratory for their sincere cooperation.

\section{References}

1. Mattoo KA, Shalabh K, Khan A. Prevalence of elder abuse among completely edentulous patients seeking complete denture prosthesis: A survey. J Indian Acad Geriatr 2009;5:177-80.

2. Babic JZ, Carek A, Jakovac M. Zirconium Oxide Ceramics in Prosthodontics. Acta Stomatol Croat 2005;39(1):25-28.

3. Antunes RP, Magalhäes F, Matsumoto W, Orsi IA. Anterior esthetic rehabilitation of all-ceramic crowns: A case report. Quintessence Int 1998;29:3840.

4. Kumar S, Mattoo KA. Staining of A Fixed Partial Denture to Restore Pre-extraction Self Image - A Case Report. JIDA 2010;4(12):573-74

5. Mattoo KA, Garg R, Gupta A and Jain N. Toxicology and biocompatibility of dental materials. Research Journal of Pharmaceutical, Biological and Chemical Sciences 2012;3(4):1091-99

6. Lakshya K, Khurshid MA, Yadav A. Achieving esthetics by adding gingival porcelain to existing prosthesis - an innovative way. Journal of Pearldent 2010;1(3):1-5 
7. Mattoo K, Singh M. Gingival Prosthesis for aesthetic correction of gummy smile. International Journal Of Research In Medical Sciences And Technology 2014;1(1):1-2

8. Shori K, Shori T, Shori D, Chavan R. Achieving Esthetic Perfection by Zirconia : A Case Report. Int J Dent Med Res 2015;1(6):146-149.

9. Kelly JR, \& Benetti P (2011) Ceramic materials in dentistry: Historical evolution and current practice Australian Dental Journal 56(1) 84-96.

10. Chang YY (2011) Maximizing esthetic results on zirconia based restorations. General Dentistry 59(6) 440-445

11. Darraj A, Mattoo KA. Full Mouth Rehabilitation Involving Occlusal Plane Correction. Journal of Medical Sciences and Clinical Research, 2017;5(9):28204-208

12. Diego AA, Santos CD, Landim KT, Elias CN. Characterization of ceramic powders used in the inceram systems to fixed dental prosthesis. Mater Res 2007;10(1):47-51 